\title{
Kinetic Study of Adsorption of Some Azo Dyes On A Thermally Catalyzed Local Bentonite Clay
}

\author{
Safwan.A.S.Aldbouni \\ University of Mosul \\ College of Education for \\ Pure Sciences \\ Department of Chemistry \\ Safwan76xxx@gmail.com
}

\author{
Ammar.A.H.Alkazraji \\ University of Mosul \\ College of Education for Pure Sciences \\ Department of Chemistry \\ ammarhamdoon@unomosul.edu.iq
}

\author{
Emad.A.S.Alhyali \\ University of Mosul \\ College of Education for \\ Pure Sciences \\ Department of Chemistry \\ emmadabd2006@yahoo.com/
}

\section{DOI: $\underline{10.33899 / \text { edusj.1999.163310 }}$}

\section{Received \\ 29/ 08 / 2018}

\section{Accepted}

$02 / 10 / 2018$

\begin{abstract}
The research is included studying the kinetic of the adsorption of two azo dyes synthesized in our laboratories on a local bentonite thermally activated . The efficiency and capacity of adsorption are calculated at the optimal conditions of adsorption. Such as the effect of dose, contact time ,pH of adsorption medium and temperature .

Four kinetic models of adsorption namely ,pseudo first and second order ,Elovich , and intraparticle diffusion have been applied on the experimental data of the adsorption system under consideration. The results showed that the studied systems are fitted to the pseudo second order model ,and the adsorption process occurs in more than one mechanism. The activation energy of adsorption of the studied system in addition to the thermodynamic functions of activation of adsorption are estimated from studying the effect of temperature on the rate constant of adsorption .
\end{abstract}

Key words: Kinetics, adsorption, azo dyes ,bentonite clay catalyst 


\title{
دراسة حركية لامتزاز بعض أصباغ الآزو على طين البنتونايت المحلي المحفز حراريا
}

\author{
عماد عبد الاله الحيالي \\ جامعة الموصل علد الاله \\ كلية التربية للعلوم الصرفة \\ قسم الكيمياء \\ Safwan76xxx@gmail.com
}

DOI: $\underline{10.33899 / \text { edusj. } 1999.163310}$

$$
\begin{aligned}
& \text { عمار أحمد حمدون } \\
& \text { جامعة الموصل عمل اجمل } \\
& \text { كلية التربية للعلوم الصرفة } \\
& \text { قسم الكيمياء }
\end{aligned}
$$

ammarhamdoon@unomo sul.edu.iq

\author{
صفوان عبد الستار

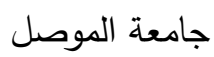

كلية التربية للعلوم الصرفة

قسم الكيمياء

emmadabd2006@yahoo.co m/

$$
\text { القبول }
$$

القبول

2018 / 10 / 02

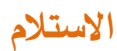

2018 / 08 / 29

\section{الخلاصة}

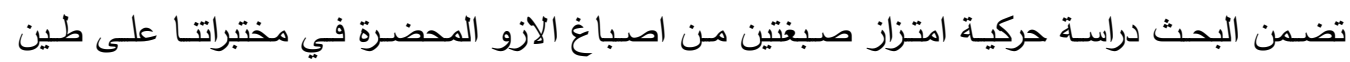

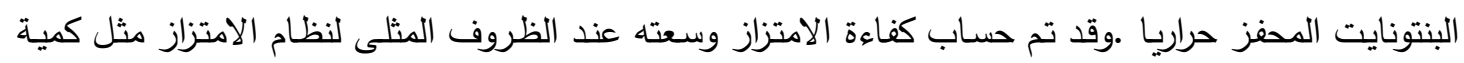

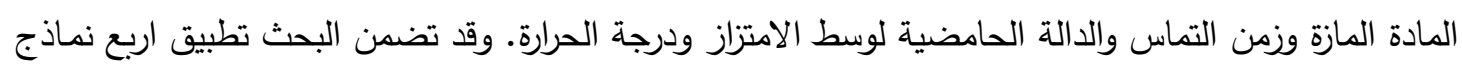

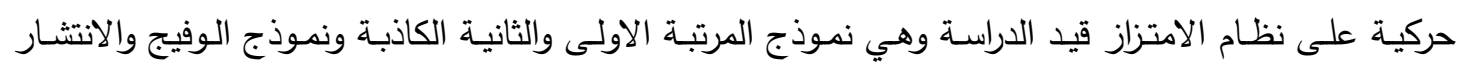

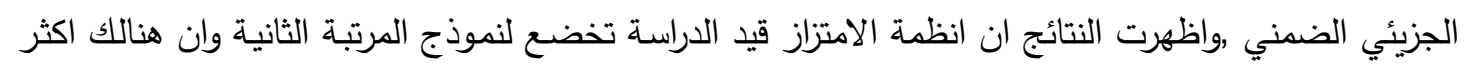

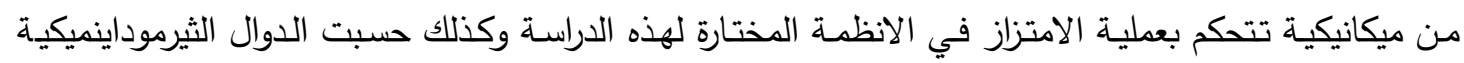
للامتزاز وطاقة تتشيط الامتزاز من خلال دراسة تأثير الحرارة على ثابت سرعة الامثيكة الامتزاز.

الكلمات المفتاحية: حركية ، امتزاز ، اصباغ الازو ، طين البنتونايت المحفز

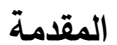

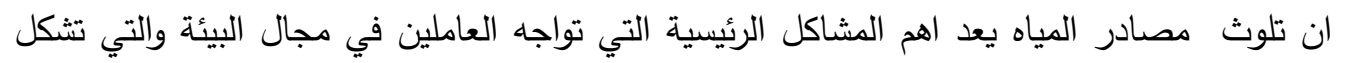
تهديدا للحفاظ على الانظمة المائية الطبيعية .ان العديد من الصناعات مثل النسيجية وصناعة الورق والبلاستكاك

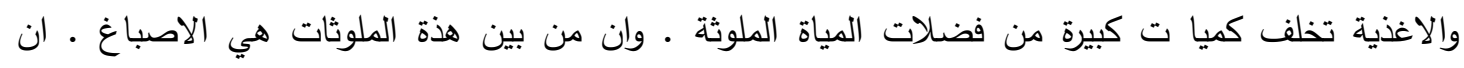
الصناعات المختلفة كالصناعات النسيجية تحدث وراءها انواع متعددة من الصبغات الصيات المحضرة والتي تطرح

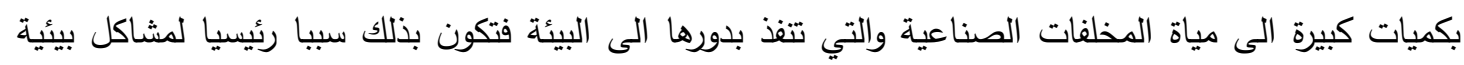

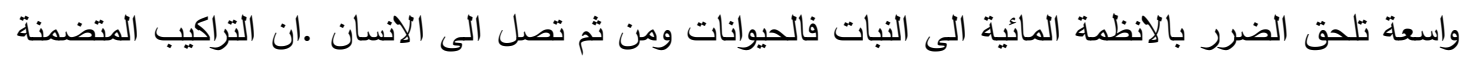

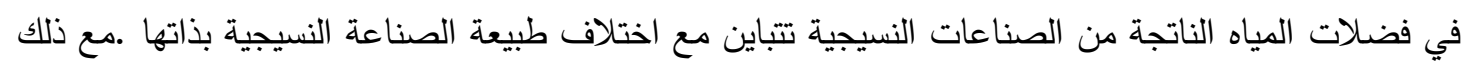

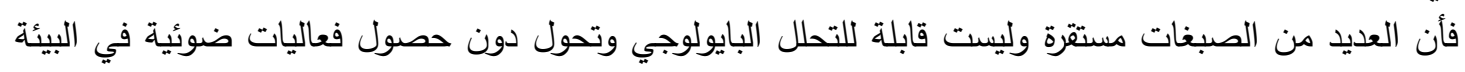

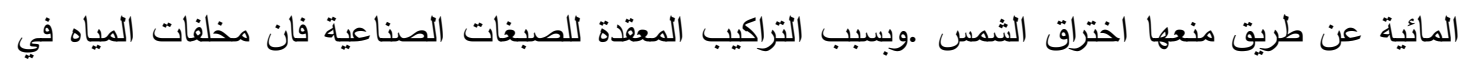

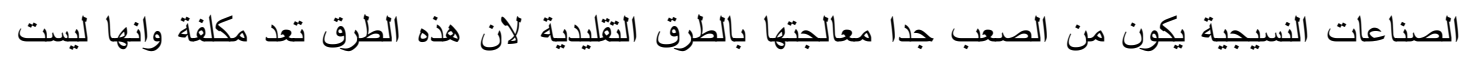

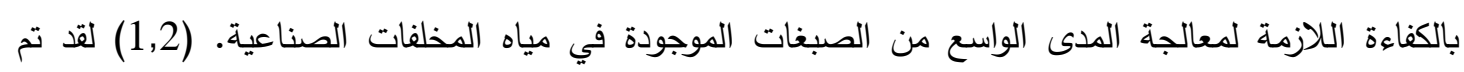

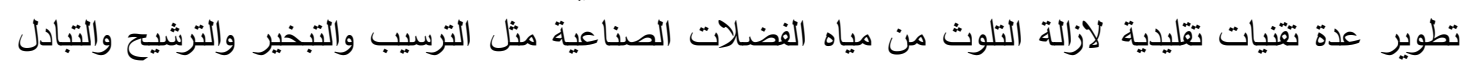

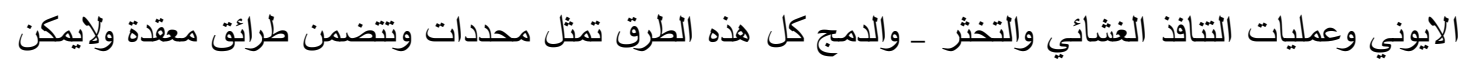
تطبيقها اتصاديا. ويعد الامتزاز احد اهم الطرق واكفاءها في ازالة التلوث والذي تم استخدامه في تطبيقات متعددة 
ومتكررة اكثر من بقية الطرق الاخرى بسبب بساطة في التصميم والتطبيق وقابلية استعادة المادة المازة بجانب

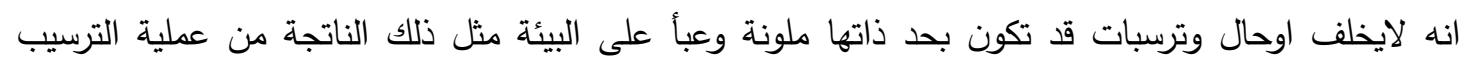

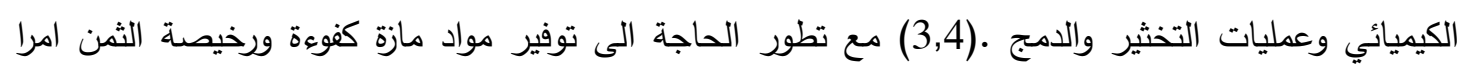

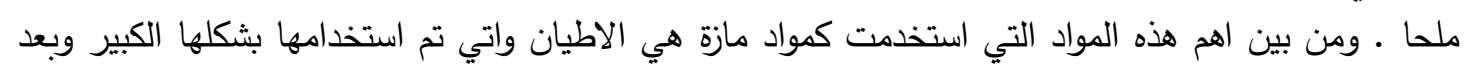
اجراء بعض التحويرات عليها (5) وقد تضمنت هذه الدراسة هذه الدراسة اختيار وكفاءة عدد من الاطيان لامتزاز

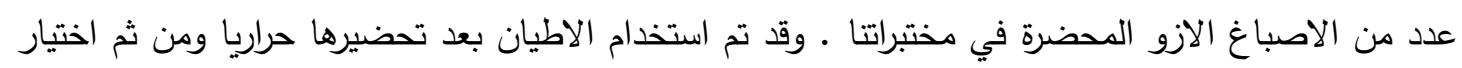

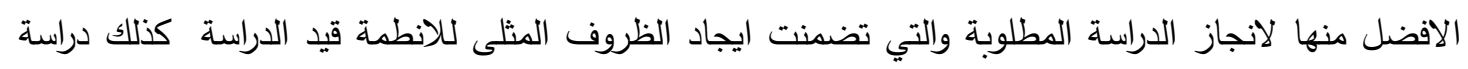

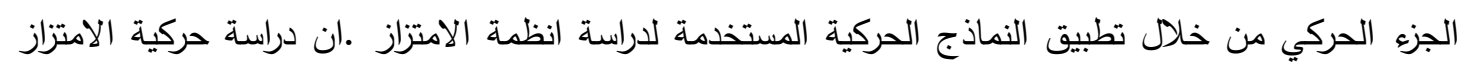

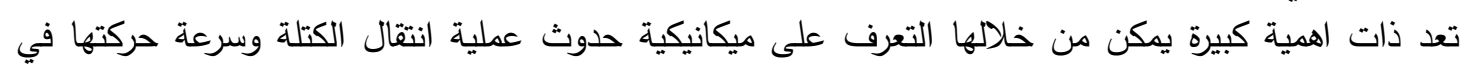

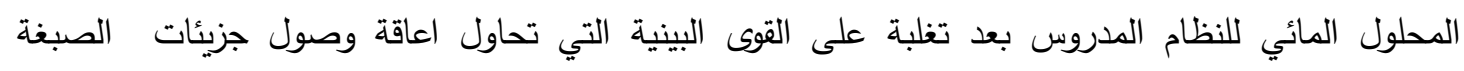

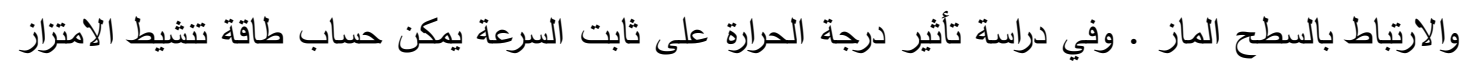

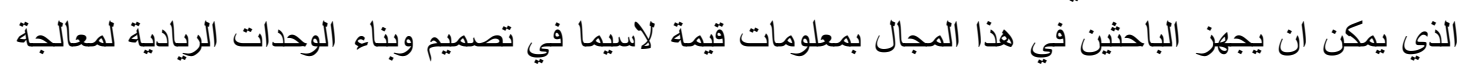
التلوثِ.

الجزء العملي

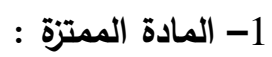

المادة الممتزة المستخدمة بهذا البحث هي عبارة عن صبغتين ازو حضرتا في مختبرتتامن تفاعل باراميثوكسي

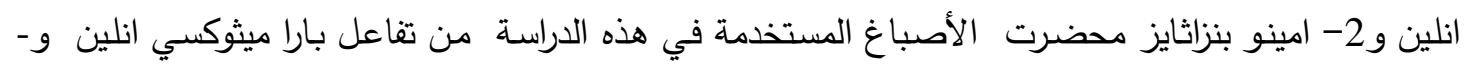

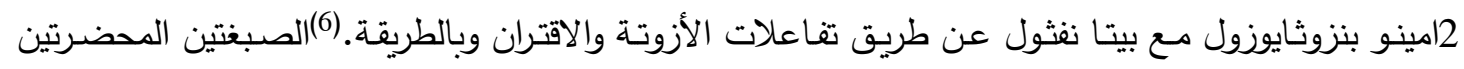

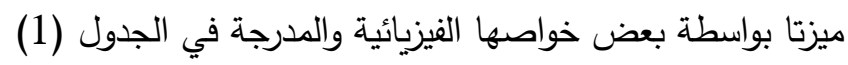
2- 2 - 2 المادة المازة: اختيرت كفاءة امتزاز عدد من الاطيان المحلية مثل السلايت والكاؤؤلين والبوكسايت وبينتونايت قرة تبة وبنتونايت

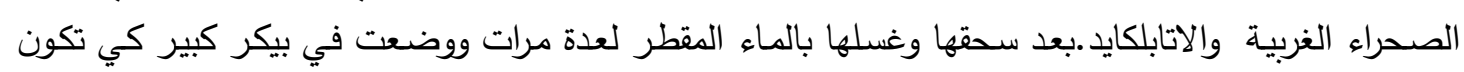

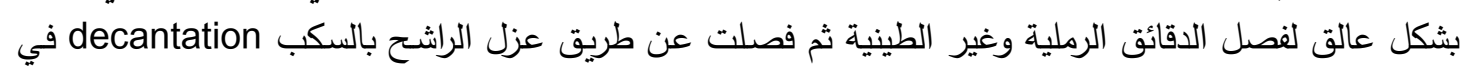

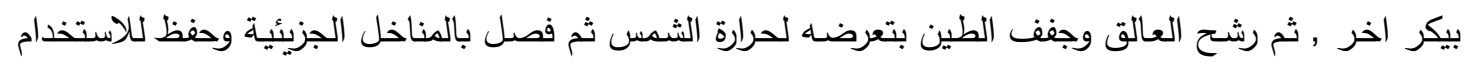

في بقية الدراسة.

الجدول(1) يوضح اشكال الصبغات التي تم تحضيرها وصفاتها

\begin{tabular}{|c|c|c|c|c|c|c|}
\hline اسم المركب & الصيغة التركيبية & اللون & M.Wt & درجة الإصهار & $\begin{array}{c}\lambda \max \\
(\mathrm{nm})\end{array}$ & $\begin{array}{c}\mathcal{E}_{\max } \\
\mathrm{L} / \mathrm{mol}\end{array}$ \\
\hline $\begin{array}{l}\text { 1(4-methoxy } \\
\text { phenyl) } \\
\text { azo-2- } \\
\text { Naphthol } \\
\text { (MOPABN) }\end{array}$ & & أسود & 278 & 166.0 & 365 & 2154 \\
\hline $\begin{array}{c}2- \\
\text { enzothiazol) } \\
1 \\
\text { azo-2- } \\
\text { naphthol } \\
\text { (BTABN) }\end{array}$ & & برتقالي & 308 & 175 & 374 & 2451.7 \\
\hline
\end{tabular}


3. تقدير تركيز المادة الممتزة

ان الطريقة التحليلية هي الاكفاء لتقدير المواد الممتزة (الاصباغ) كونها مواد ملونة هي الطريقة الطيفية .وقد استخدم جهاز المطياف (Spectrophotometer (T92+). المتوفر في مختبراتتا لتقدير تراكيز الصبغات في المحاليل قيد الدراسة وكخطوة اولى لإتمام العمل المزمع إنجازه في تحديد قيمة أقصى طول

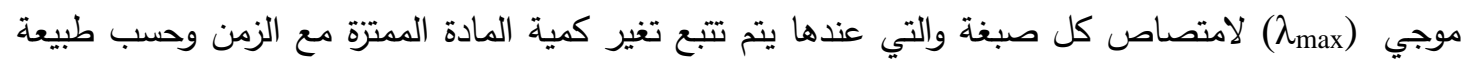

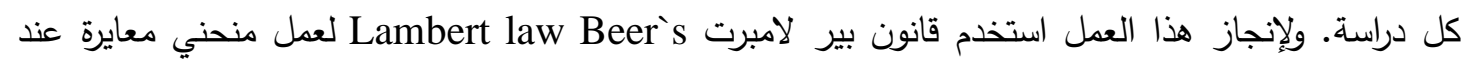
قيمة max لكل صبغة وذلك من رسم العلاقة بين الامتصاص والتركيز وحسب المبن المعادلة:

$\mathrm{A}=\varepsilon \mathrm{CL}-----(1)$

إذ ان (A) تمثل الامتصاص و (ع) هو معامل الامتصاص المولاري(Liter.mol-1.cm-1) و (C) هو تركيز

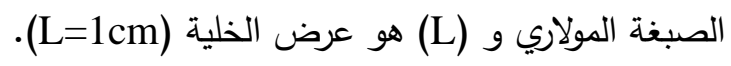

وقد اعتمد منحني المعايرة لتقدير كمية المادة الممتزة من قياس التركيز المتبقي للصبغة عند الاتزان( Ce (C) (mg/L) (C (mg/L)

وقد استخدم مصطلح (mg/g) (me) للتعبير عن سعة امتزاز المادة المازة للصبغة بالمعادلة الآتية $\mathrm{q}=\frac{C_{i}-C_{e}}{M} \times \mathrm{V}-----(2)$

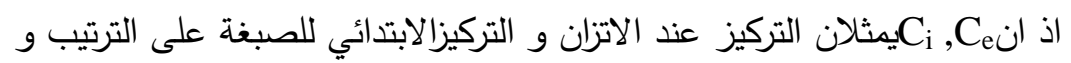

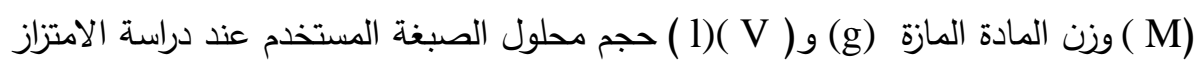

كما يمكن حساب النسبة المئوية للصبغة المادة(الممتزة) أو ما يسمى بكفاءة الامتزاز باستخدام

$\%$ Adsorption $=\frac{C_{i}-C_{e}}{C_{i}} \times 100$

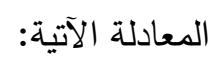

4. - بريقة الدفعة الواحدة:

انجزت هذة الطريقـة مـن خـلال رج كميـات محددة من محاليـل الصبغات بتراكيز مختلفـة وباستخدام كميات متساوية من المادة المازة (الطين) وغيرت الظروف حسب نوع الدراسة المنجزة .وقد استخدمت دوارق مخروطية

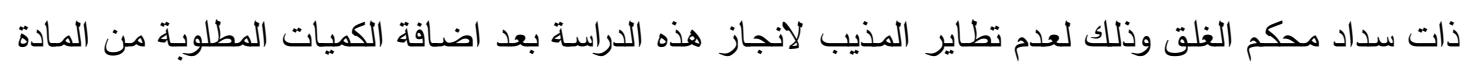

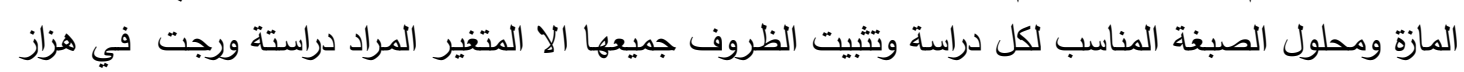

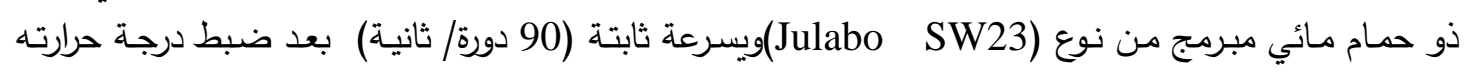
وباستخدام محرار زئبقي للمساعدة. 5.

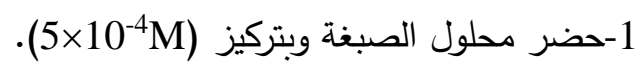

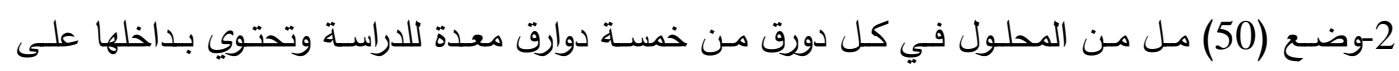
(0.075mg) يكفي لترشيح الصبغة المتبقية. 3- رجت المحاليل بسرعة ثابتة داخل الهزاز والذي يحوي الحمام المائي والمثبت عند درجة حرارة معينـة تم ضبطها مسبقاً, ثم شحت المحاليل في أزمان مختلفة (5 و10 و20 و30 و40 و و50 و60 و و90) دقيقة. 4-قدرت كمية المادة الممتزة والمتبقية باستخدام منحني المعايرة للصبغة. 5-أعيدت العملية نفسها لجميع الصبغات قيد الدراسـة وعند درجـات حراريـة (288 و 293 و و 298 و و 313 و323) مطلقة, وقد تم تطبيق البيانات المحصل عليها على نماذج المعادلات الحركية . 


\section{النتائج والمناقشة}

الطريقة التحليلية:

إن من أبرز متطلبات هذه الدراسة هي أيجاد طريقة تحليلية لتقدير كمية المادة الممتزة قبل وبعد عملية

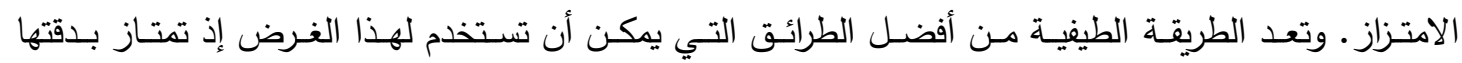
وحساسيتها للتراكيز الواطئة ولا تتضمن أية تداخلات مع مواد أخرى موجودة ضمن النظام المدروس .
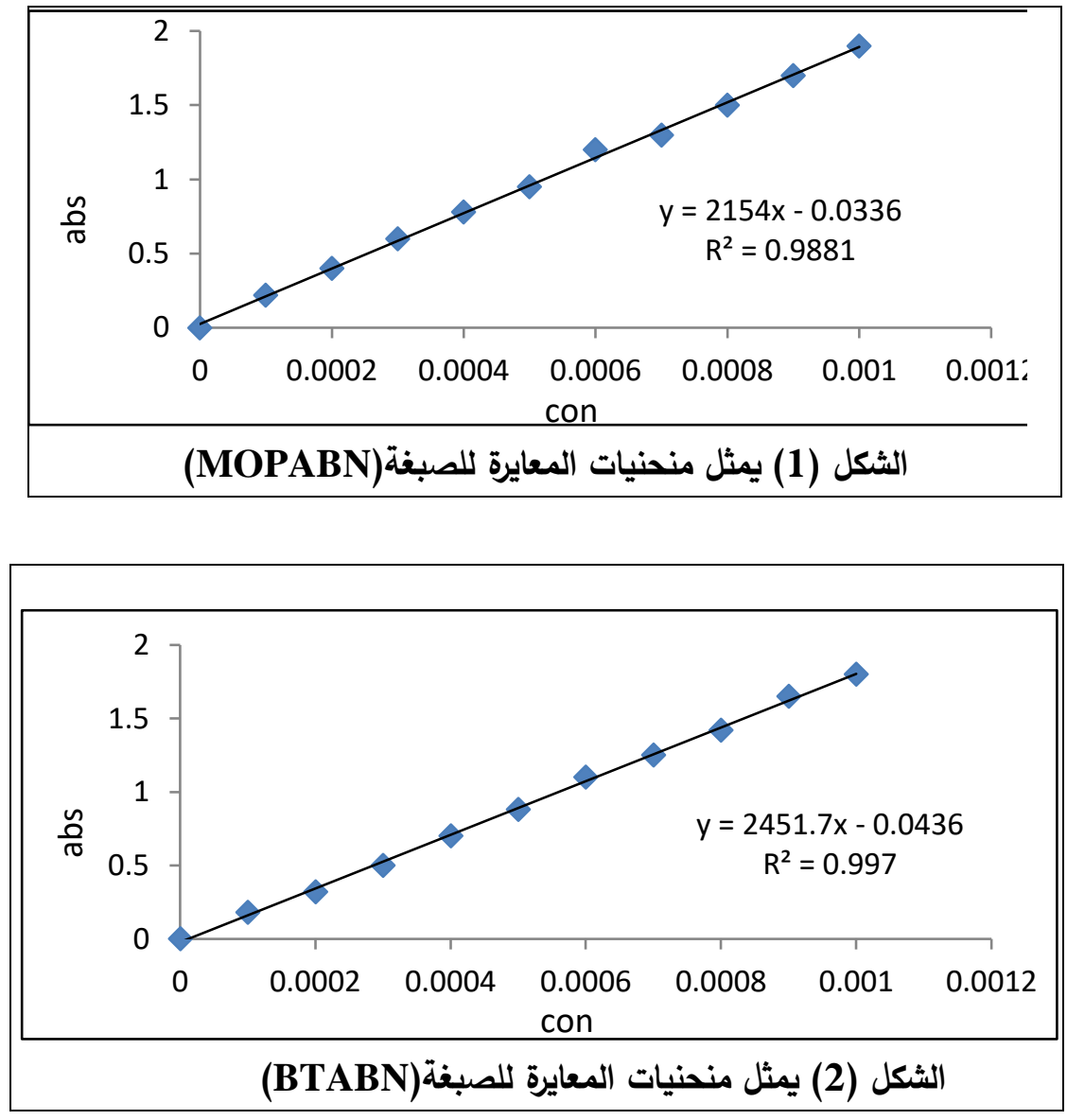

اختيار المادة المازة :

في هذه الدراسة اختير عد من الأطيان كمادة مازة للصبغات قيد الدراسة وهذه الاطيات هي السـايليت والكاؤولين

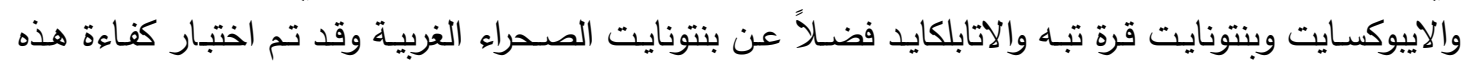

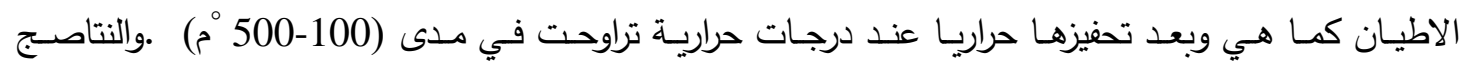
المحصل عليها ادرجت في الجدول (2) 
جدول(2) يوضح كفاءة امتزاز صبغة (BTABN )وبدرجة حرارة (20 مم) وبتركيز (M 5x10 ) ووزن (0.075g)

\begin{tabular}{|c|c|c|c|c|c|c|}
\hline \multirow[t]{2}{*}{ اسم الطين } & \multirow[t]{2}{*}{ غير معالج } & \multicolumn{5}{|c|}{ معالجة بدرجات حرارية (م) } \\
\hline & & 100 & 200 & 300 & 400 & 500 \\
\hline \%Bentonite(w) & 52.5 & 58.3 & 65.2 & 68.1 & 71.4 & 32.0 \\
\hline \%Ataplgaid & 40.2 & 48.6 & 40.1 & 52.2 & 68.2 & 34.9 \\
\hline \%Bentonite(k.t) & 35.7 & 37.2 & 41.2 & 48.3 & 50.6 & 11.8 \\
\hline \%Bauxite & 20.1 & 22.1 & 29.4 & 35.7 & 40.9 & 20.5 \\
\hline$\%$ Clite & 18.1 & 19.8 & 13.2 & 13.8 & 14.0 & 3.0 \\
\hline \%Alkaolin & 13.1 & 14.7 & 14.5 & 15.6 & 15.8 & 7.3 \\
\hline
\end{tabular}

من ملاحظة الجدول(2) نجد ان زيادة درجة الحرارة من الحالة الغير معالجة الى الحالة الحالة المعالجة حراريا

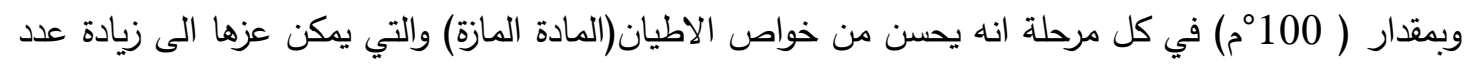

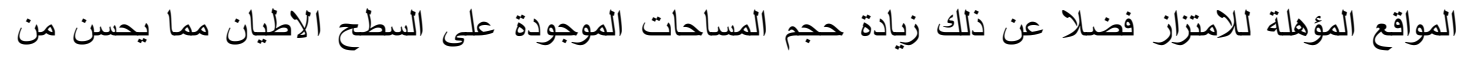

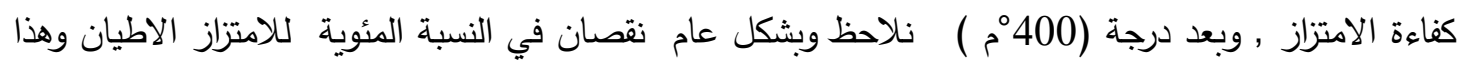

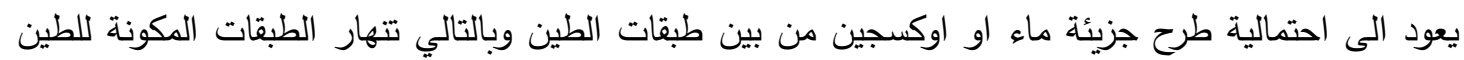

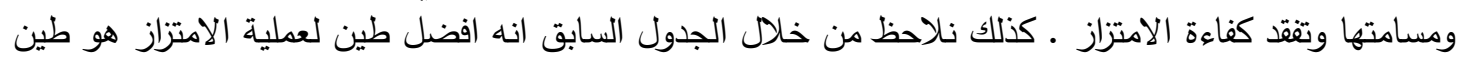

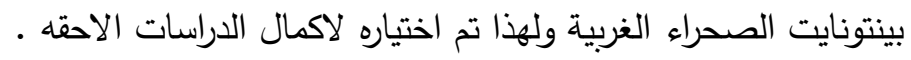

تأثير زمن التماس: انجزت هذه الدراسة بعد تثبتت كل المتغيرات التي يمكن أن تؤثر في كفاءة الامتزاز مثل درجة حرارة

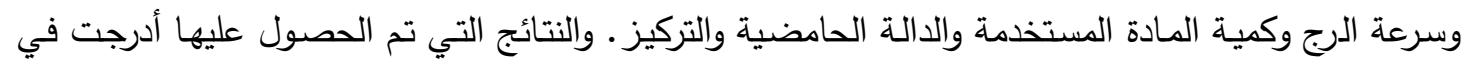
الجدول (3) ولجميع المواد المازة المختارة لإنجاز هذه الدمانة الدراسة.

جدول (3) تأثير الزمن على النسبة المئوية للامتزاز للصبغات قيد الدراسة باستخدام (0.075g) من الطين المعالج

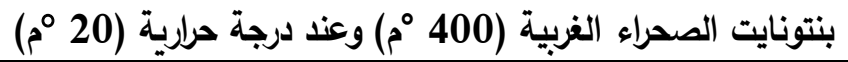

\begin{tabular}{|c|c|c|c|c|c|}
\hline اسم المركب & $\begin{array}{c}\text { Time }(\min \\
)\end{array}$ & $\mathrm{C}_{\mathrm{i}}(\mathrm{mg} / \mathrm{l})$ & $\mathrm{C}_{\mathrm{t}}(\mathrm{mg} / \mathrm{l})$ & $\mathrm{q}_{\mathrm{e}}(\mathrm{mg} / \mathrm{g})$ & الامتزاز المئوية \\
\hline \multirow{8}{*}{ MOPABN } & 5 & \multirow{8}{*}{$\left(5 \times 10^{-4} M\right)$} & 46.6 & 61.6 & 66.4 \\
\hline & 10 & & 44.0 & 63.3 & 68.3 \\
\hline & 20 & & 43.1 & 63.9 & 68.9 \\
\hline & 30 & & 42.5 & 64.3 & 69.4 \\
\hline & 40 & & 41.9 & 64.7 & 69.8 \\
\hline & 50 & & 41.3 & 65.1 & 70.2 \\
\hline & 60 & & 41.2 & 65.2 & 70.3 \\
\hline & 90 & & 40.1 & 65.9 & 71.1 \\
\hline \multirow{8}{*}{ BTABN } & 5 & \multirow{8}{*}{$\left(5 \times 10^{-4} M\right)$} & 50.6 & 68.9 & 67.1 \\
\hline & 10 & & 48.3 & 70.4 & 68.6 \\
\hline & 20 & & 47.5 & 71.0 & 69.1 \\
\hline & 30 & & 45.2 & 72.5 & 70.6 \\
\hline & 40 & & 44.8 & 72.8 & 70.9 \\
\hline & 50 & & 44.0 & 73.3 & 71.4 \\
\hline & 60 & & 43.9 & 73.4 & 71.4 \\
\hline & 90 & & 43.6 & 73.6 & 71.6 \\
\hline
\end{tabular}




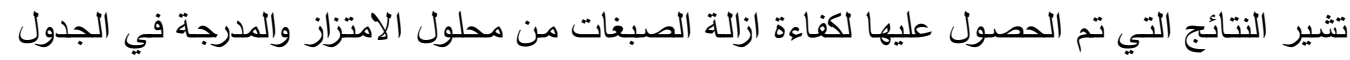

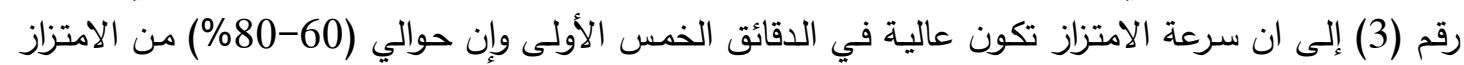

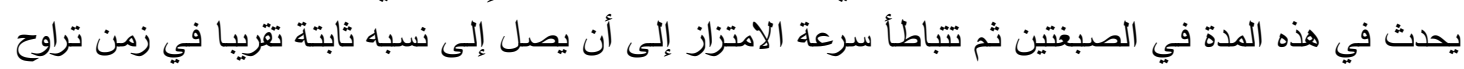

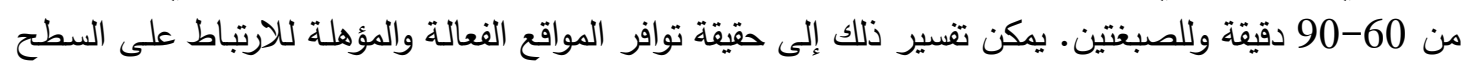

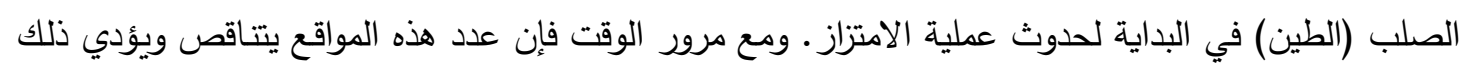

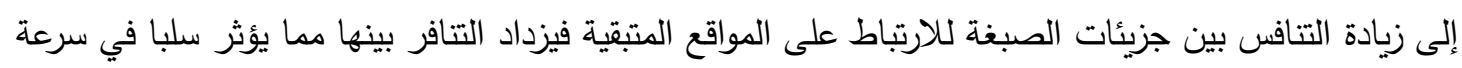
وكفاءة ارتباطها بالسطح.

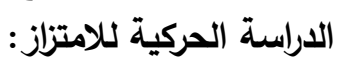

إن ما يميز حركية الامتزاز أنها تحدث بأكثر من سرعة واحدة ثابتة كما هو المعروف عن دراسـة حركية

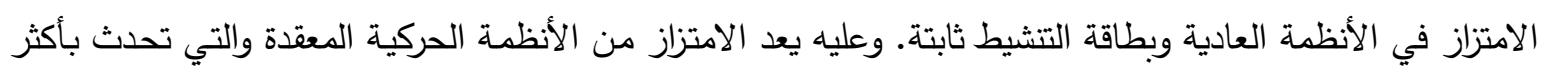

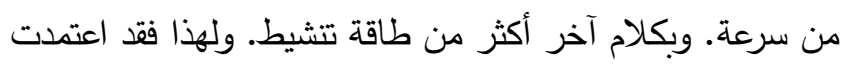

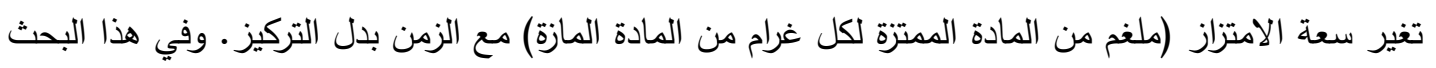

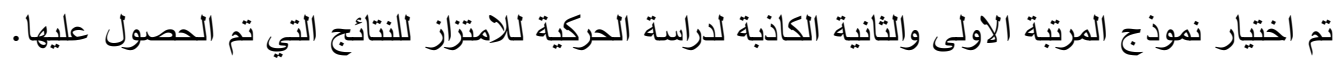
معادلة المرتبة الأولى الكاذبة:

طبق انموذج المرتبة الأولى أو مـا تعرف بمعادلة (Lagergren) على البيانات العملية للامتزاز للأصباغ المعتمدة بهذا البحث. وتم ذلك من خلال تطبيق المعادلة التالية:

$$
\ln \left(q_{e}-q_{t}\right)=\ln q_{e}-k_{1} t----
$$

حيث رسمت العلاقة بين (n $\left(\mathrm{q}_{\mathrm{e}}-\mathrm{q}_{\mathrm{t}}\right.$ مقابل الزمن (دقيقة) والتي يفترض أن تعطي علاقات خطية بميل مقدراه (-

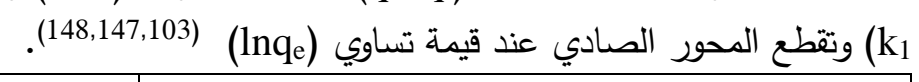

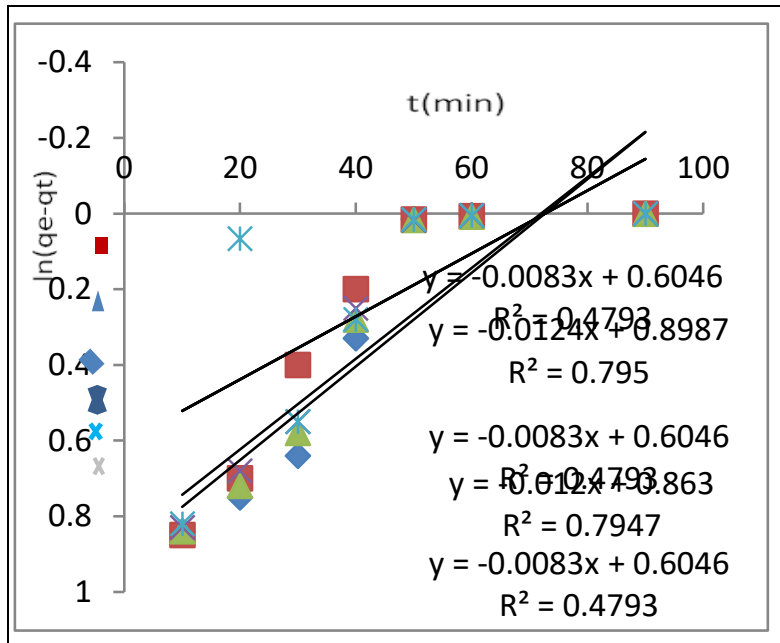

شكل(4) يوضح العلاقة بين $t$ مقابل $t$ للمركب BTABN

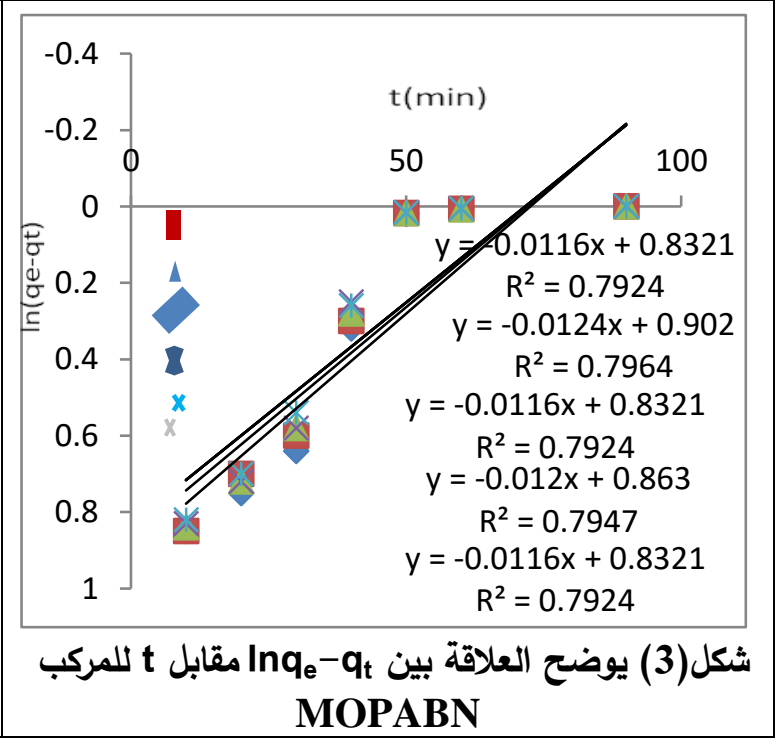


جدول (4) قيم وثوابت السرعة وسعة الامتزاز النظرية والعملية للمرتبة الأولى وعند درجات حرارية مختلفة وتركيز

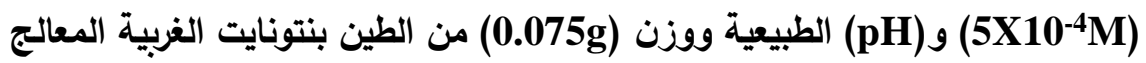

\begin{tabular}{|c|c|c|c|c|c|}
\hline اسم المركب & $\operatorname{Temp}\left(K^{\circ}\right)$ & $\begin{array}{c}\text { qe(calc) } \\
(\mathrm{mg} / \mathrm{g})\end{array}$ & $\begin{array}{c}\mathrm{K}_{1} \\
\text { (gmg.min) }\end{array}$ & $\begin{array}{l}\text { qe(exp) } \\
(\mathrm{mg} / \mathrm{g})\end{array}$ & $\mathbf{R}$ \\
\hline \multirow{5}{*}{ MOPABN } & 288 & 2.464 & 0.012 & 66.3 & 0.8900 \\
\hline & 293 & 2.714 & 0.013 & 65.9 & 0.8918 \\
\hline & 303 & 2.52 & 0.013 & 65.9 & $\mathbf{0 . 8 9 7 0}$ \\
\hline & 313 & 2.720 & 0.013 & 65.4 & 0.9119 \\
\hline & 323 & 2.912 & 0.014 & 64.7 & 0.8899 \\
\hline \multirow{5}{*}{ BTABN } & 288 & 2.699 & 0.013 & 74.3 & 0.1554 \\
\hline & 293 & 2.680 & 0.013 & 72.6 & 0.8948 \\
\hline & 303 & 2.559 & 0.012 & 72.4 & 0.8949 \\
\hline & 313 & 2.516 & 0.012 & 72.4 & 0.9088 \\
\hline & 323 & 2.444 & 0.012 & 71.1 & 0.8960 \\
\hline
\end{tabular}

أن أنظمة الامتزاز قيد الدراسة لا تخضع لتفاعل المرتبة الأولى الكاذبة يشار إلى ذلك من خلال معاملات الارتباط

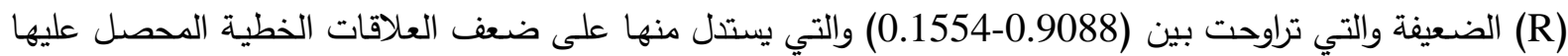

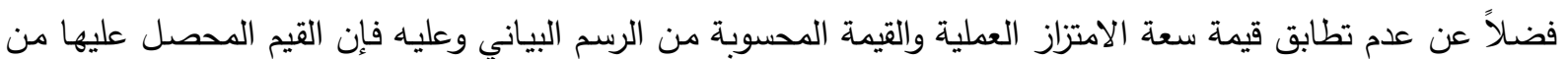

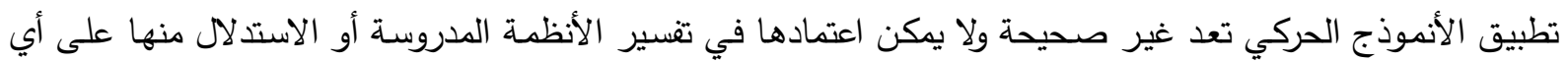

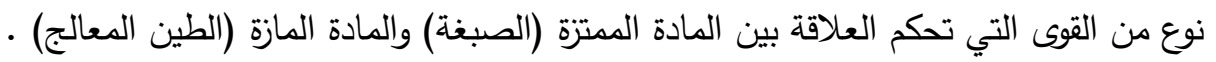

\section{Pseudo second order equation}

معادلة المرتبة الثانية الكاذبة:

طبق انموذج معادلة المرتبـة الثانية الكاذبة على البيانات العملية للامتزاز باستخدام نفس المـادة المازة (الطين المعالج) وعند نفس الظروف المعتمدة عند تطبيق معادلة المرتبة الأولى الكاذبة من درجة حرارة وتركيز الصبغات والدالة الدالة

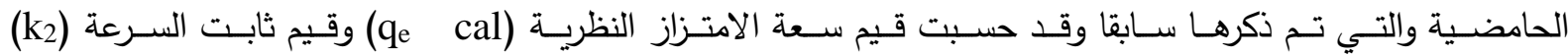
من خلال تطبيق المعادلة التالية:

$$
\frac{t}{q_{t}}=\frac{1}{k_{2} q_{e}^{2}}+\frac{1}{q_{e}} t
$$

ورسم العلاقة البيانيـة بين (t/qt) مقابل الزمن وحسـاب قيمـة سعة الامتزاز وثابت السـرعة (k2) من ميل ومقطع

$$
\text { الخطوط المستقيمة المحصل عليها على التوالي }
$$

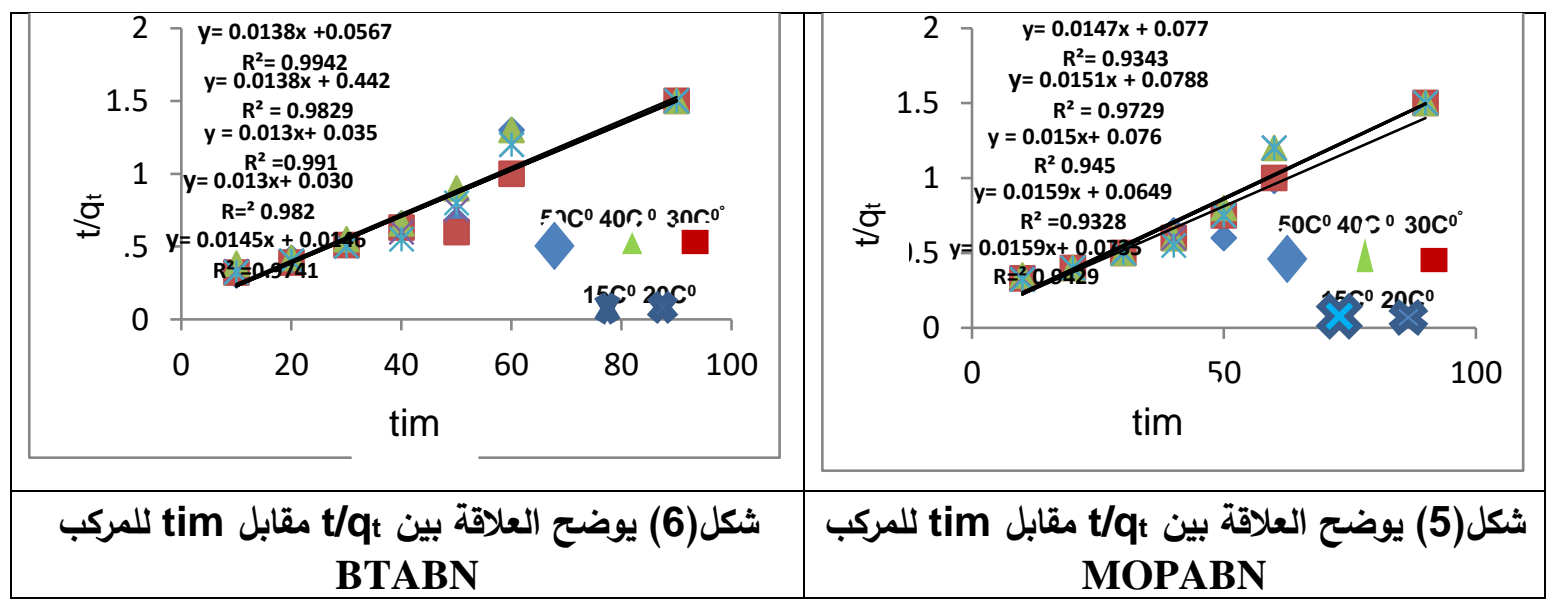




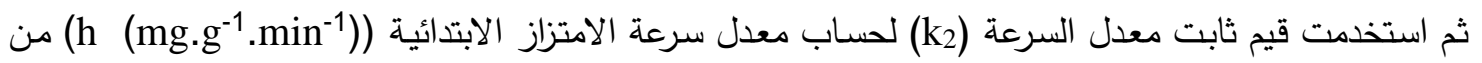

المعادلة (5).

$h=k_{2}\left(q_{e}\right)^{2}$

إن النتائج التي تم الحصول عليها من تطبيق هذا الأنموذج الحركي على البيانات العمليـة للامتزاز للأنظمـة

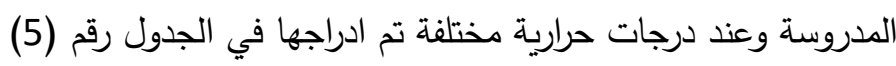

جدول (5) قيم وثوابت السرعة وسعة الامتزاز النظرية والعملية للمرتبة الثانية الكاذبة وعند درجات حرارية مختلفة وتركيز (5X10-4M) و) والطبيعية ووزن (0.075g) من طين بنتونايت الغربية المعالج

\begin{tabular}{|c|c|c|c|c|c|c|}
\hline اسم المركب & $\operatorname{Temp}\left(K^{\circ}\right)$ & $\begin{array}{c}\text { qe(calc) } \\
(\mathrm{mg} / \mathrm{g})\end{array}$ & $\begin{array}{c}\text { k2 } \\
\text { (gmg.min) }\end{array}$ & $\begin{array}{c}\text { h } \\
\text { (mg.g.min) }\end{array}$ & \begin{tabular}{|c|} 
qe(exp) \\
$(\mathrm{mg} / \mathrm{g})$ \\
\end{tabular} & $\mathbf{R}$ \\
\hline \multirow{5}{*}{ MOPABN } & 288 & 71.42 & 0.0025 & 12.75 & 66.3 & 0.9664 \\
\hline & 293 & 66.6 & 0.0029 & $\mathbf{1 2 . 8 6}$ & 65.9 & 0.9859 \\
\hline & 303 & 76.92 & 0.0048 & 28.4 & 72.4 & 0.9954 \\
\hline & 313 & 66.6 & 0.0031 & 13.75 & 65.4 & 0.9705 \\
\hline & 323 & 66.6 & 0.0035 & 15.52 & 64.7 & 0.9654 \\
\hline \multirow{5}{*}{ BTABN } & 288 & 76.92 & 0.0030 & 17.75 & 75.3 & 0.9969 \\
\hline & 293 & 76.92 & 0.0038 & 29.22 & 73.6 & 0.9909 \\
\hline & 303 & 76.92 & 0.0048 & 28.400 & 73.4 & 0.9954 \\
\hline & 313 & 76.92 & 0.0056 & 33.13 & 73.1 & 0.9909 \\
\hline & 323 & 71.43 & 0.0139 & 70.92 & 72.1 & 0.9869 \\
\hline
\end{tabular}

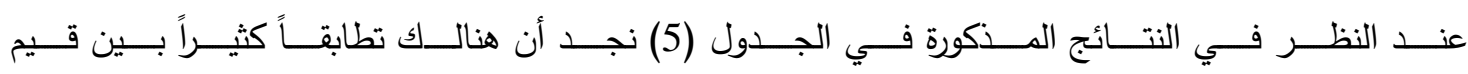
(qe exp) عليها كانت بين (0.9969-0.9664) وهذه تشير إلى علاقات خطية قوية عند تطبيق هذا الأنموذج الحركي على بلى بيانات

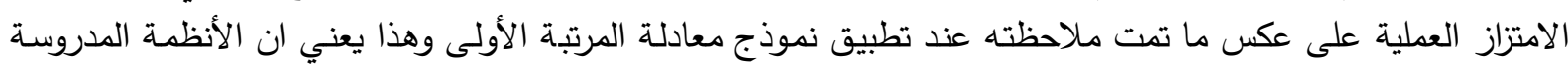

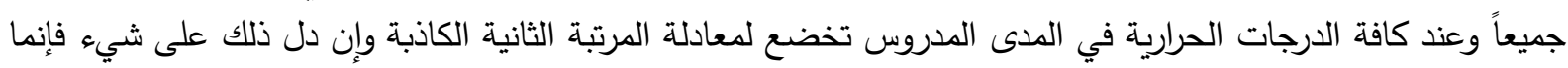

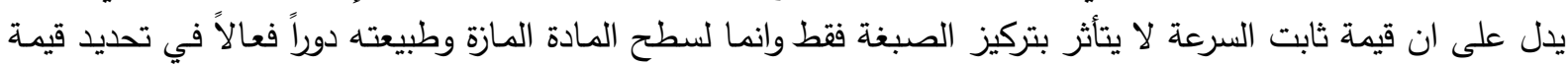

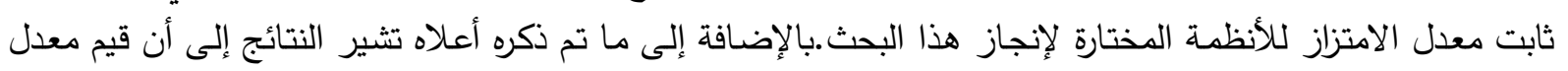

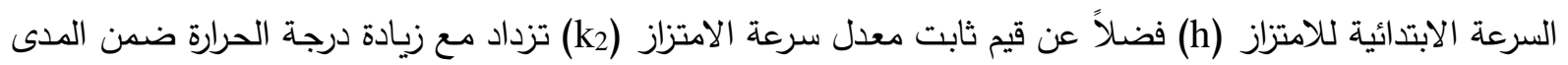

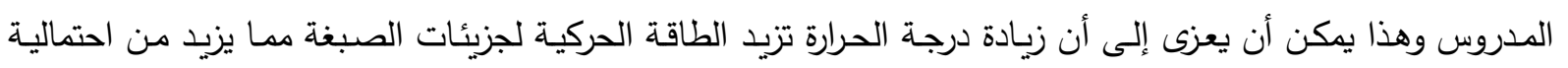

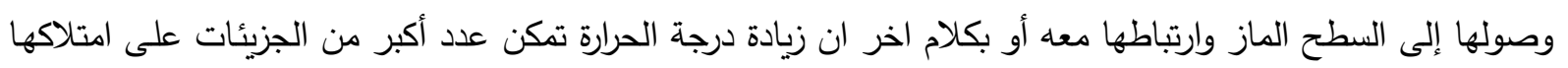

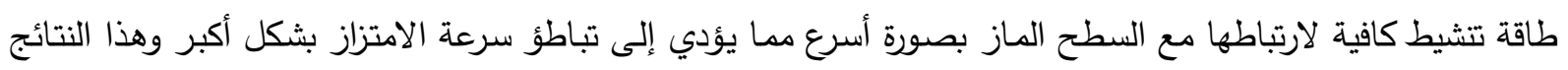

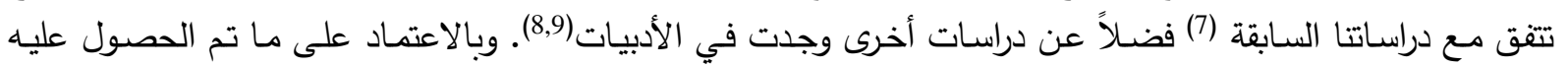

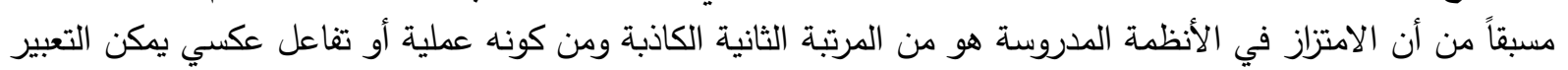
عن عملية الامتزاز بالمعادلة الآتية: من الإن

Dye + c Dye $\underset{k-2}{\stackrel{k+2}{\rightleftharpoons} \ldots . . . . c ~}$

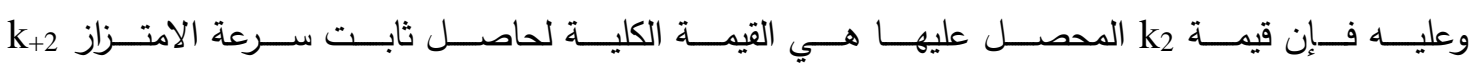
وثابت سرعة الابتزاز . (k-2) 
$k_{2}=k_{+2}+k_{-2}$

$\mathbf{K}=\mathbf{k}+2 / \mathbf{k}-2$

ومن علاقة ثابت الاتزان لثابت السرعة الممثلة بالمعادلة الآتية:

ومن معرفة قيم K وk2 يمكن حساب قيم كل من k+2 وk-2 وعند الدرجات الحرارية في المدى المختار لإنجاز

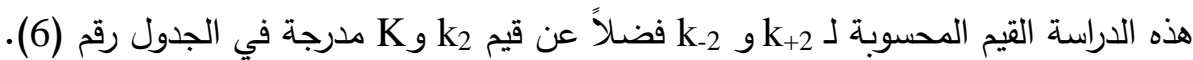

جدول (6) يوضح قيم ثوابت السرعة وعند درجات حرارية مختلفة وعند تركيز (5x10-3M) للصبغات قيد الراسة وعند pH طبيعية

\begin{tabular}{|c|c|c|c|c|c|}
\hline أسم المركب & $\begin{array}{c}\text { Temp } \\
\left(\mathbf{K}^{\circ}\right)\end{array}$ & $\begin{array}{c}\text { K } \\
\text { ثابت التوازن }\end{array}$ & $\begin{array}{c}\mathrm{k}_{2} \\
\text { (g.mg-1.min-1) }\end{array}$ & $\begin{array}{c}\mathrm{k}+2 \\
(\mathrm{~g} \cdot \mathrm{mg}-1 . \mathrm{min}-1)\end{array}$ & $\begin{array}{c}\mathrm{k}-2 \\
\text { (g.mg-1.min-1) }\end{array}$ \\
\hline \multirow{5}{*}{ MOPABN } & 288 & 2.51 & 0.0025 & 0.00179 & 0.00071 \\
\hline & 293 & 2.46 & 0.0029 & 0.00207 & 0.00083 \\
\hline & 303 & 2.44 & 0.0048 & 0.00341 & 0.00139 \\
\hline & 313 & 2.39 & 0.0031 & 0.00219 & 0.00091 \\
\hline & 323 & 2.36 & 0.0035 & 0.00246 & 0.00104 \\
\hline \multirow{5}{*}{ BTABN } & 288 & 2.73 & 0.0030 & 0.00220 & 0.00080 \\
\hline & 293 & 2.58 & 0.0038 & 0.00274 & 0.00106 \\
\hline & 303 & 2.51 & 0.0048 & 0.00344 & 0.00136 \\
\hline & 313 & 2.50 & 0.0056 & 0.00400 & 0.00160 \\
\hline & 323 & 2.36 & 0.0139 & 0.00977 & 0.00413 \\
\hline
\end{tabular}

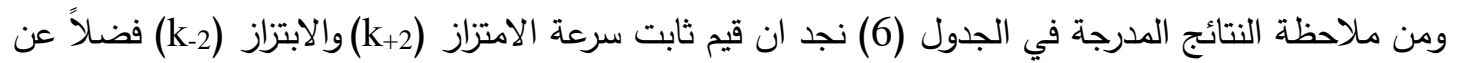

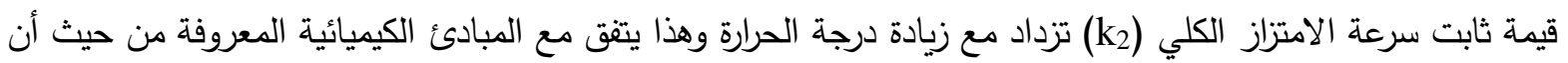

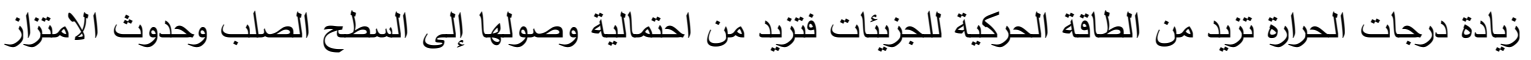

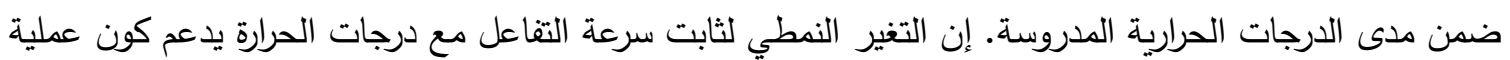
الامتزاز هي من المرتبة الثانية وهو عكس ما تم ملاحظته في قيم (k1) المحصل عليها من تطبيق معادلة التفاعل من $\mathrm{k}=\mathrm{Ae}^{-\mathrm{E}^{*} / \mathrm{RT}}$

المرتبة الأولى. ومن تطبيق معادلة ارهينيوس العنبه

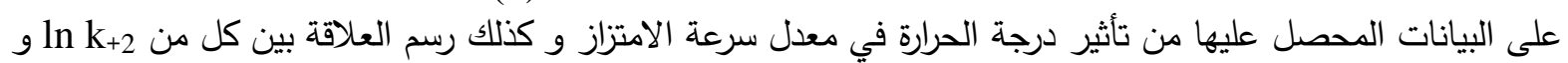

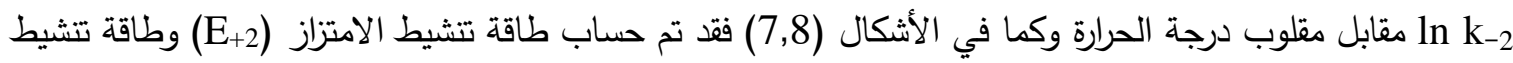

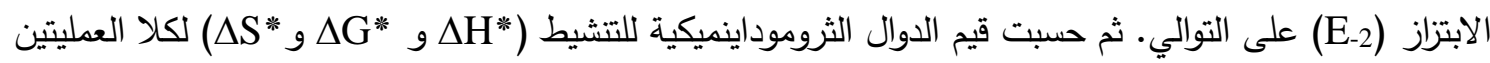

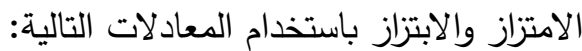

$\Delta \mathrm{H}^{*}=\mathrm{E}-\mathrm{RT}$

$\Delta S^{*}=R\left[\ln A-\ln \left(\frac{K T}{h}\right)-1\right]$

$\Delta \mathrm{G}^{*}=\Delta \mathrm{H}^{*}-\mathrm{T} \Delta \mathrm{S}^{*}$ 

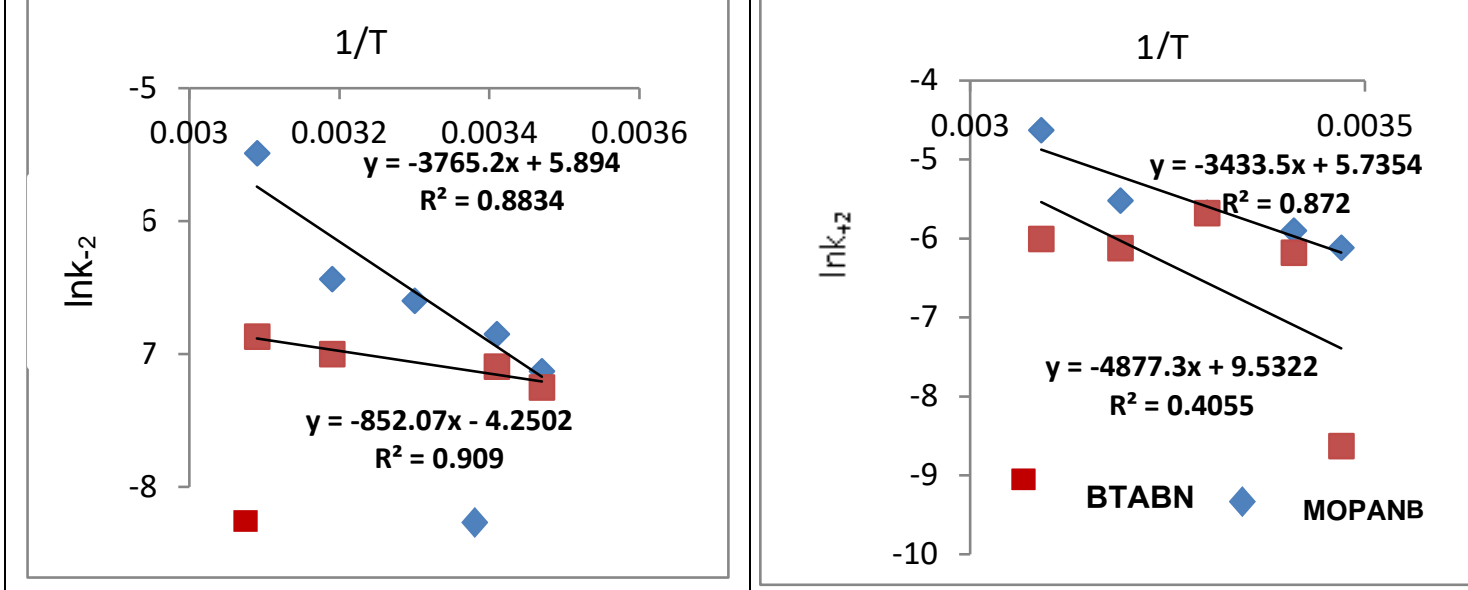

شكل (8) العلاقة بين Ink مقابل 1/T

شكل (7) العلاقة بين Ink مقابل 1/T

جدول (7) قيم الدوال الثرموداينميكية للتنشيط بالاتجاه الامامي في درجة (288K)

\begin{tabular}{|c|c|c|c|c|}
\hline اسم المركب & $\mathrm{E}_{+2}\left(\right.$ K.J.mol $\left.^{-1}\right)$ & $\begin{array}{c}\Delta \mathbf{H}^{*} \\
\left(\mathrm{~K}^{\prime} . \mathrm{mol}^{-1}\right) \\
\end{array}$ & 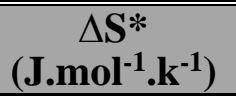 & $\begin{array}{c}\Delta \mathbf{G}^{*} \\
\left(\mathrm{~K}^{\prime} . \mathrm{mol}^{-1}\right) \\
\end{array}$ \\
\hline MOPABN & 40.547 & 38.152 & -188.57 & 92.460 \\
\hline BTABN & 28.541 & 26.146 & -220.140 & 89.546 \\
\hline
\end{tabular}

جدول (8) قيم الدوال الثرموداينميكية للتشيط بالاتجاه الخلفي في درجة (288K)

\begin{tabular}{|c|c|c|c|c|}
\hline \hline اسم المركب| & $\begin{array}{c}\text { E-2 (K.J.mol } \\
\text { 1) }\end{array}$ & $\begin{array}{c}\Delta \mathbf{H}^{*} \\
\left(\mathbf{K . J . m o l}^{-1}\right)\end{array}$ & $\begin{array}{c}\Delta \mathbf{S}^{*} \\
\left(\mathbf{J . m o l}^{\mathbf{- 1}} \cdot \mathbf{k}^{\mathbf{- 1}}\right)\end{array}$ & $\begin{array}{c}\Delta \mathbf{G}^{*} \\
\left({\mathbf{K} . J . m^{-1}}^{-1}\right)\end{array}$ \\
\hline MOPABN & 7.083 & 4.688 & -185.78 & 48.80 \\
\hline BTABN & 31.302 & 28.907 & -218.80 & 91.98 \\
\hline
\end{tabular}

ومن خلال ملاحظة النتائج المبينة في الجدولين اعلاه يمكن الإشارة إلى ما يأتي:

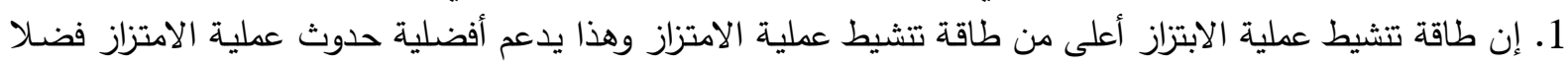

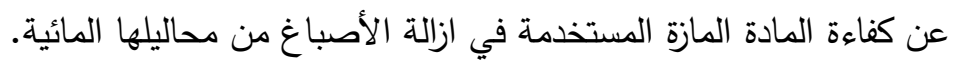

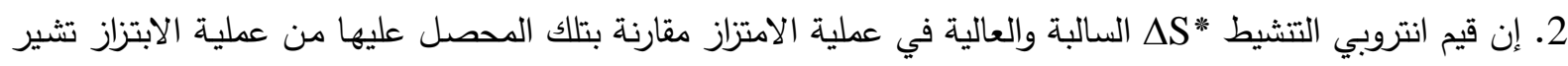

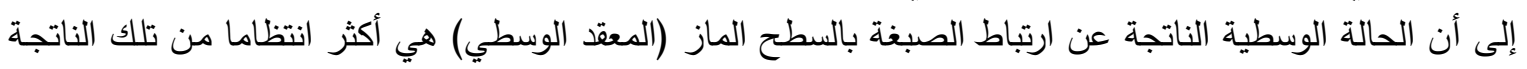

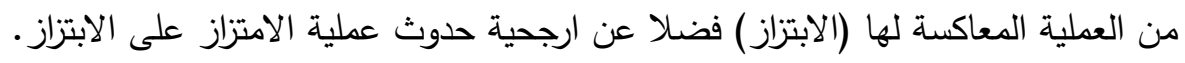

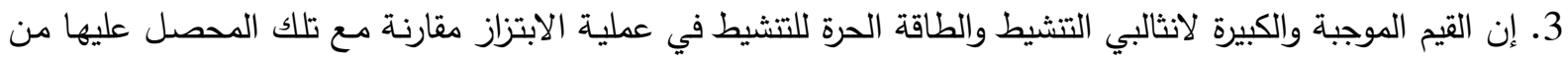

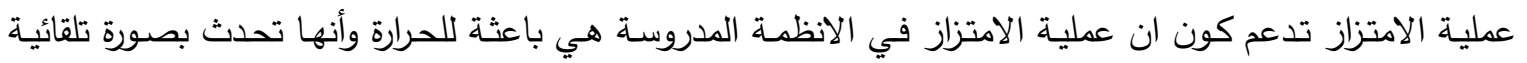
بعكس ما هو عليه الحال في عملية الابتزاز •

تعد معادلة الوفيج إحدى النماذج المستخدمة والمعروفة في الدراسات الحركية للامتزاز • إن معادلة معدل السرعة 
للتفاعل لهذا الانموذج تعتمد على سعة الامتزاز ويمكن التعبير عن هذه المعادلة بالصيغة التكاملية بالشكل الآتي:

$\mathrm{qt}=1 / \beta \ln (\alpha \beta)+1 / \beta \ln (\mathrm{t})$

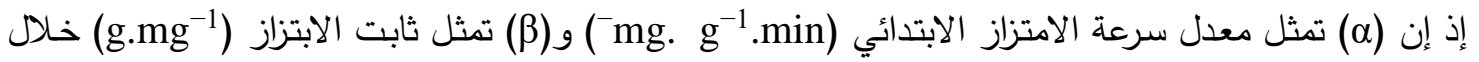

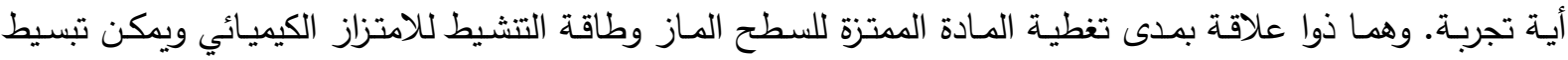

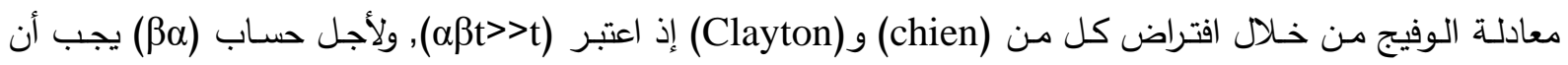
نحصل على علاقة خطية من رسم (qt) مقابل (t) واللذان يمثلان قيمة كل من المقطع والميل على التوالي.

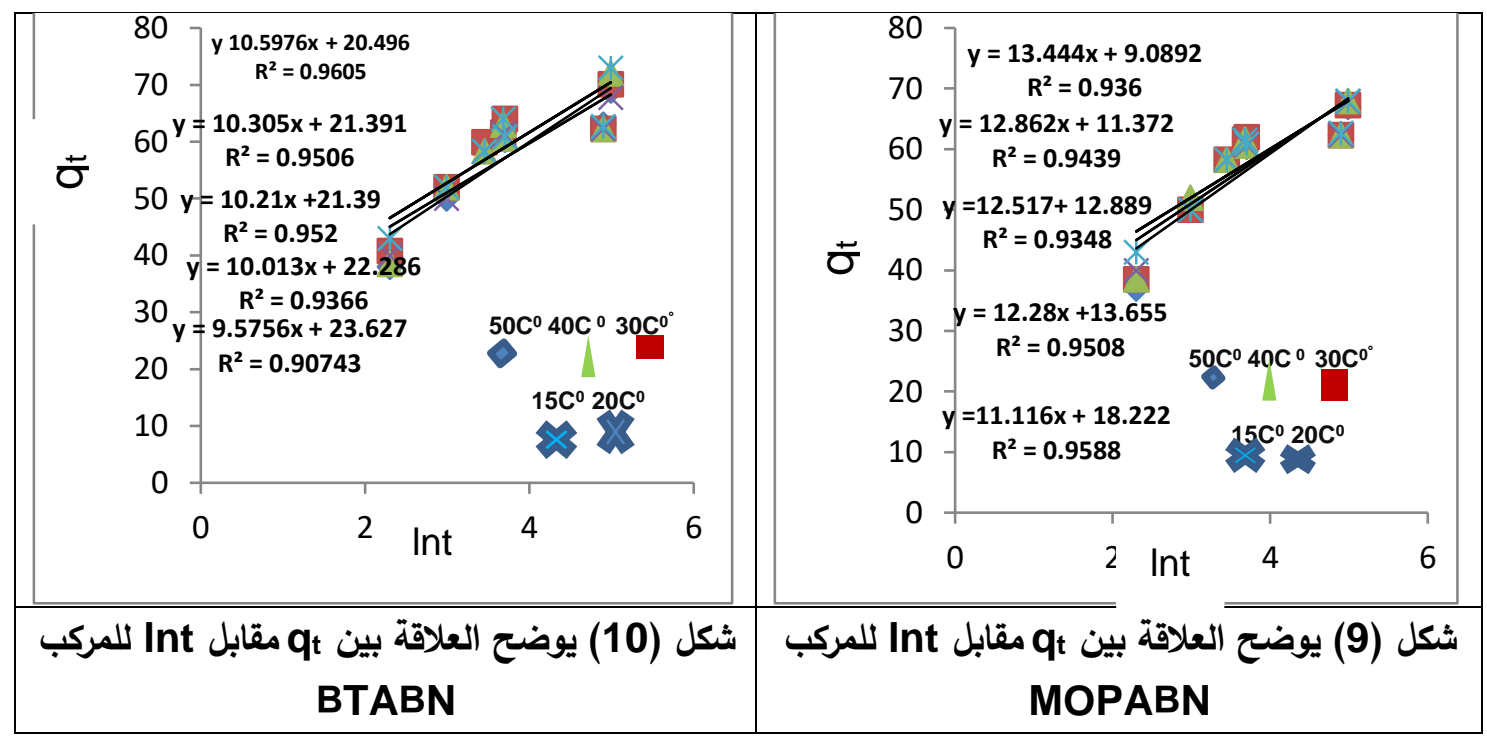

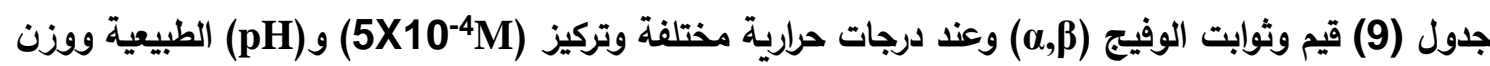

\begin{tabular}{|c|c|c|c|c|}
\hline اسم المركب & $\operatorname{Temp}\left(\mathrm{K}^{\circ}\right)$ & $\begin{array}{c}\boldsymbol{\beta} \\
\text { (g.mg) }\end{array}$ & $\begin{array}{c}\alpha \\
(\mathbf{m g} \text { g.min }) \\
\end{array}$ & $\mathbf{R}$ \\
\hline \multirow{5}{*}{ MOPABN } & 288 & 0.074 & 26.430 & 0.9674 \\
\hline & 293 & 0.077 & 31.132 & 0.9710 \\
\hline & 303 & 0.079 & 35.042 & 0.9664 \\
\hline & 313 & 0.081 & 37.320 & 0.9746 \\
\hline & 323 & 0.090 & 57.270 & 0.9787 \\
\hline \multirow{5}{*}{ BTABN } & 288 & 0.094 & 73.314 & 0.9797 \\
\hline & 293 & 0.097 & 82.175 & 0.9746 \\
\hline & 303 & 0.097 & 82.913 & 0.9757 \\
\hline & 313 & 0.099 & 92.699 & 0.9674 \\
\hline & 323 & 0.104 & 112.842 & 0.9523 \\
\hline
\end{tabular}

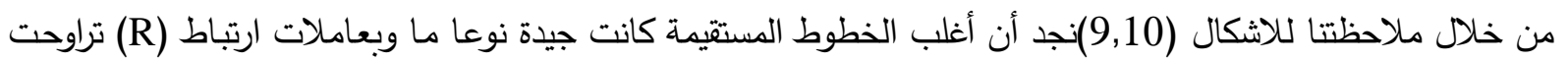

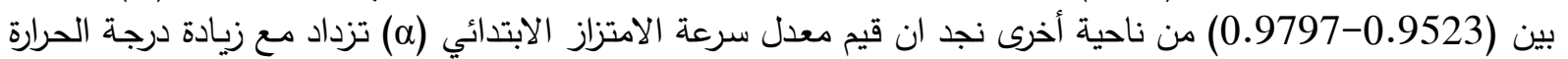

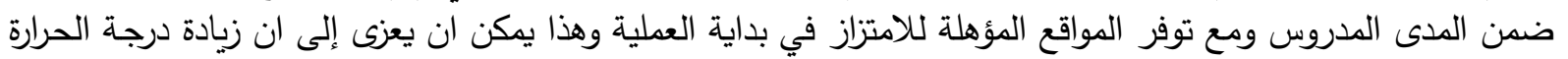




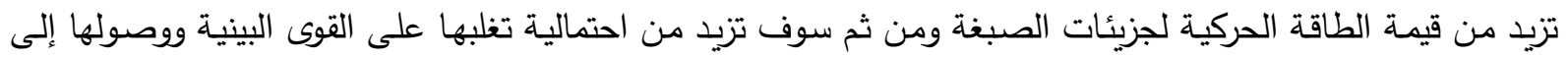

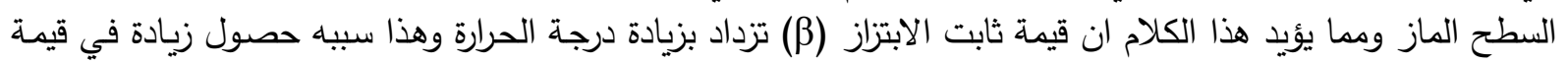

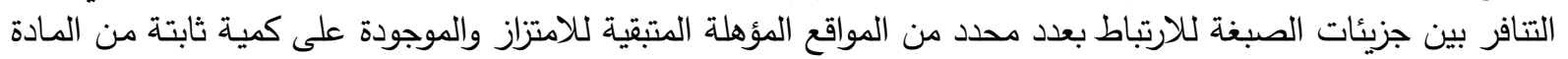

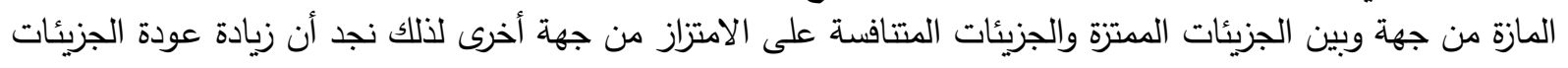

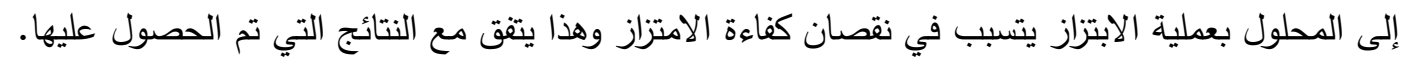

انموذج الانتشار الجزيئي الضمني: The intrapartical diffusion model

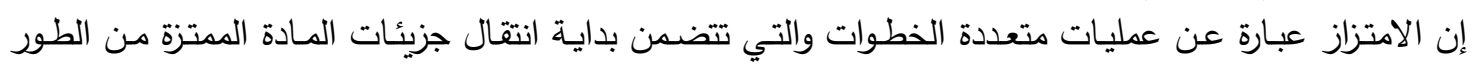

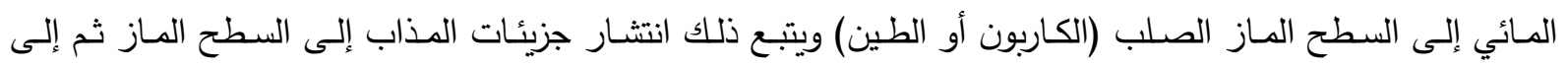

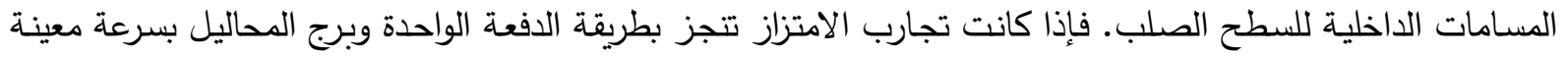

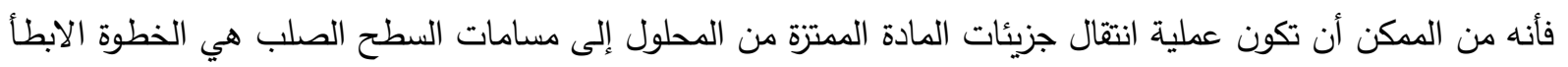

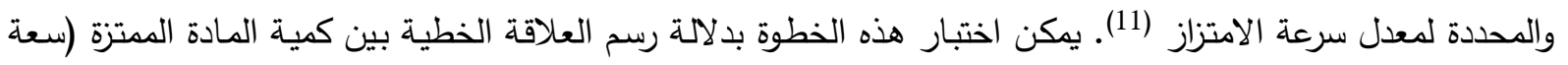

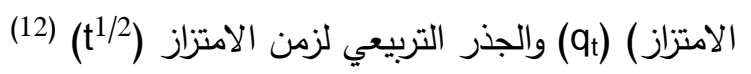

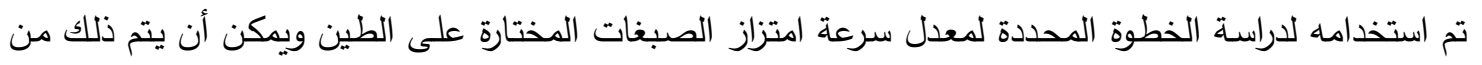
$\mathrm{q}_{\mathrm{t}}=\mathrm{K}_{\text {diff }} \mathrm{t}^{1 / 2}+\mathrm{C}$ خلال المعادلة والتي يعبر عنها بالآتي: وعند رسم العلاقـة بين (qt) والجذر التربيعي لزمن الامتزاز (t/2) يمكن حسـاب قيمـة (C) من مقطع الخط

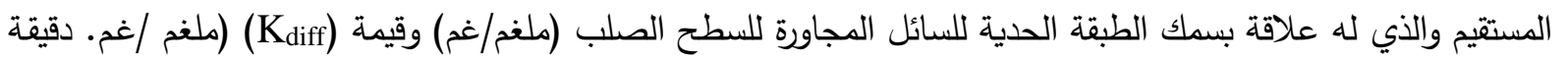

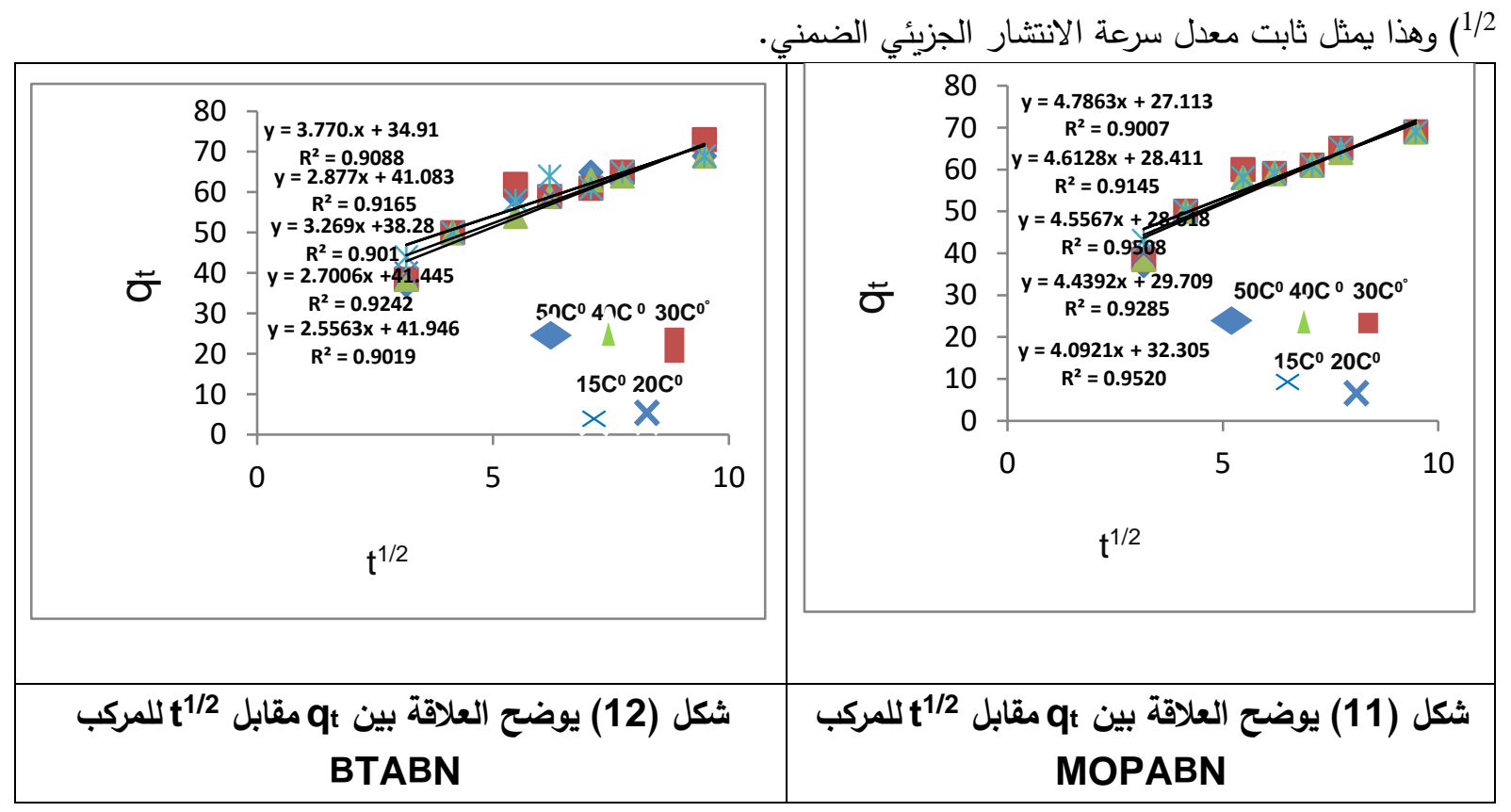


جدول(10) قيم ثوابت الانتشار الجزيئي الضمني (C,Kdiff) ومعاملات الارتباط وعند درجات حرارية مختلفة وتركيز

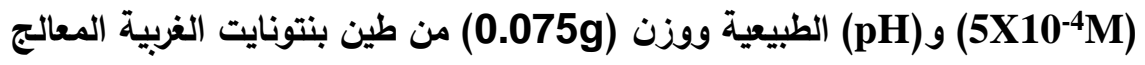

\begin{tabular}{|c|c|c|c|c|}
\hline اسم المركب & $\operatorname{Temp}\left(K^{\circ}\right)$ & $\begin{array}{c}\text { Kdiff } \\
\text { (mg.g.min) }\end{array}$ & $\begin{array}{c}\mathrm{C} \\
(\mathrm{mg} / \mathrm{g}) \\
\end{array}$ & $\mathbf{R}$ \\
\hline \multirow{5}{*}{ MOPABN } & 288 & 4.786 & 27.11 & 0.9486 \\
\hline & 298 & 4.612 & 28.41 & 0.9560 \\
\hline & 303 & 4.556 & 28.61 & 0.9539 \\
\hline & 313 & 4.439 & 29.70 & 0.9633 \\
\hline & 323 & 4.092 & 32.30 & 0.9757 \\
\hline \multirow{5}{*}{ BTABN } & 288 & 3.770 & 34.91 & 0.9528 \\
\hline & 293 & 3.827 & 37.92 & 0.9407 \\
\hline & 303 & 3.241 & 38.28 & 0.9488 \\
\hline & 313 & 3.700 & 41.44 & 0.9612 \\
\hline & 323 & 2.556 & 41.94 & 0.9492 \\
\hline
\end{tabular}

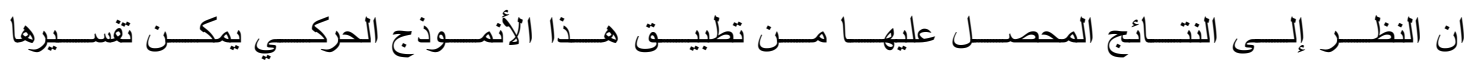

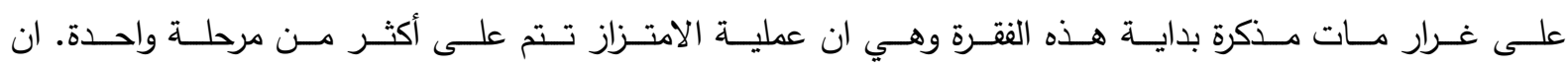

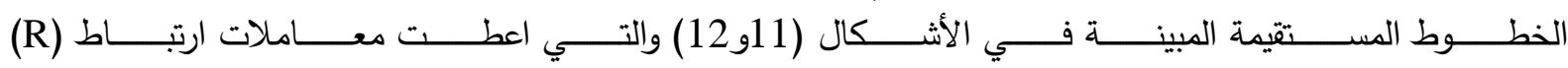

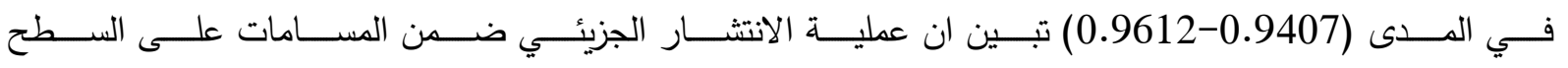

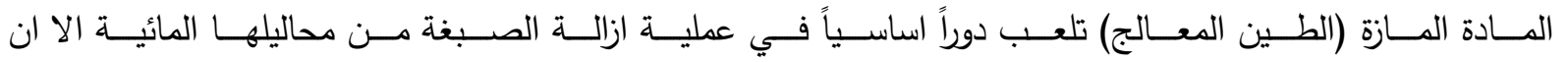

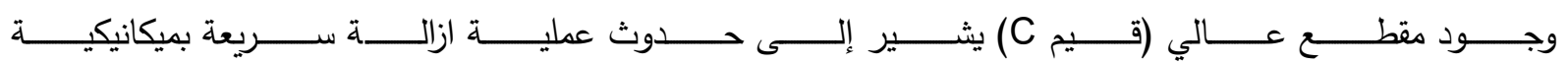

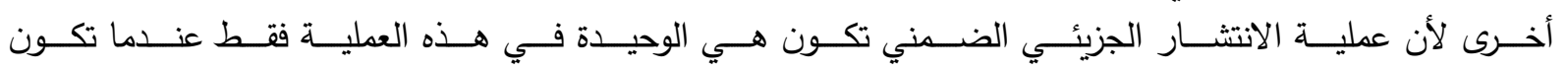

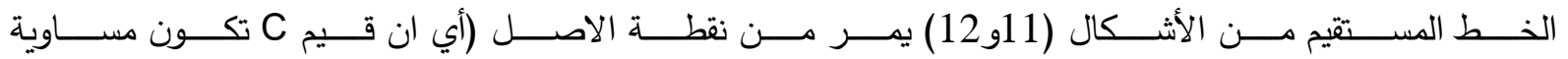

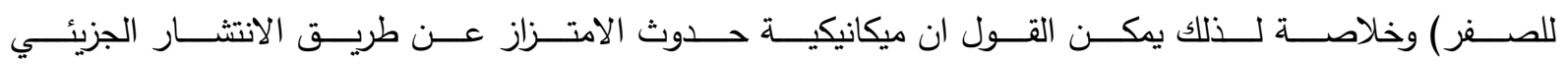

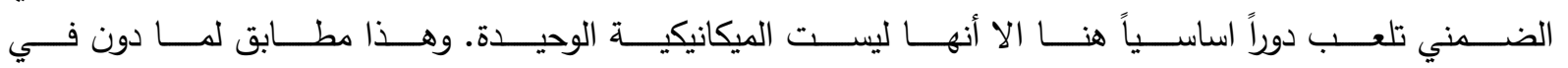
دراسات أخرى (14,15,16, 


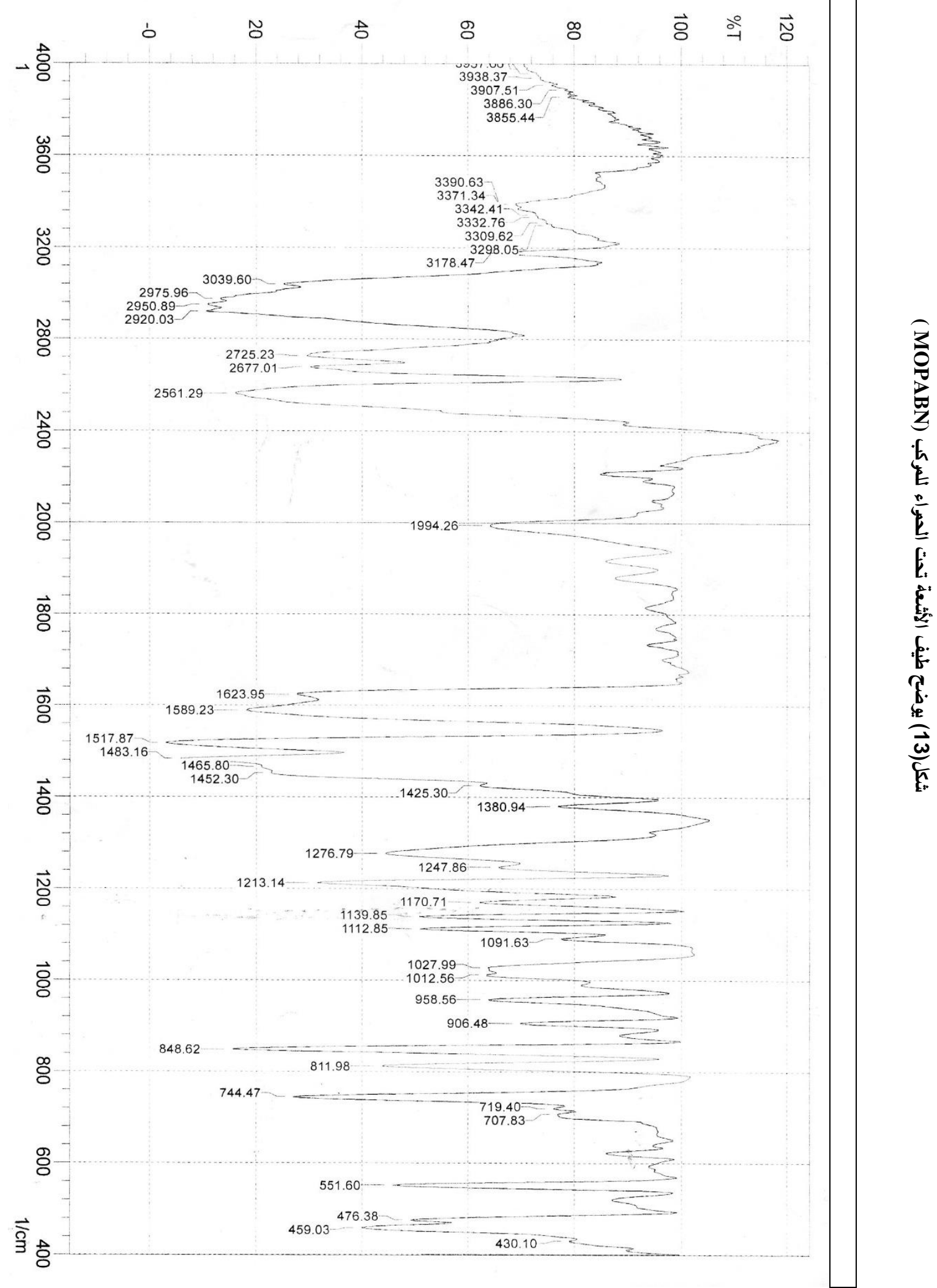




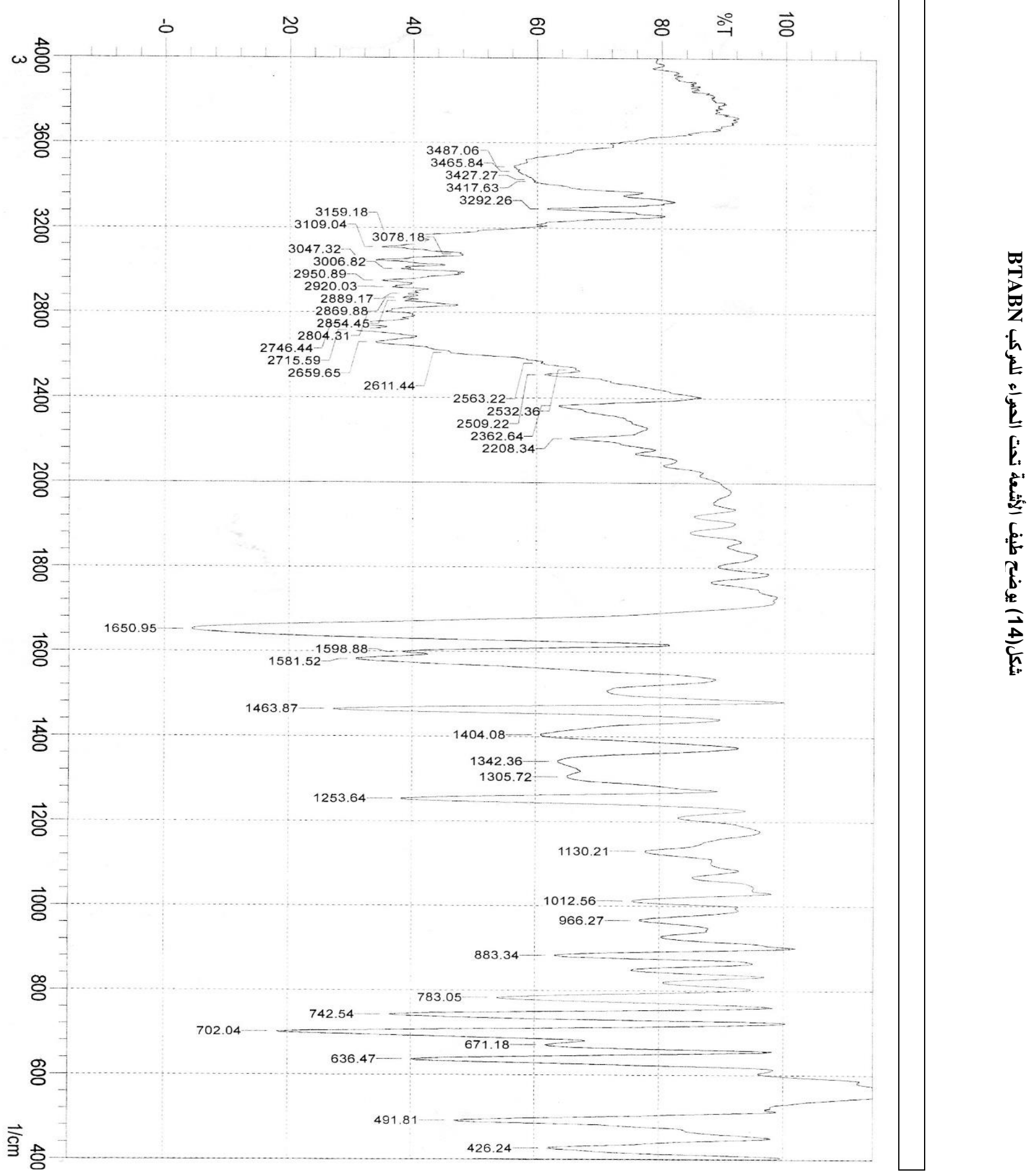




\section{المصادر}

1.Ahmad AAand Hameed BH.Journal of Hazardous Materials 175(1-3):298-303,(2010)

2.Demarchi CA, CamposMand Rodrigues CA. Journal of Environmental Chemical Engineering 1(4): 1350-1358,(2013).

3.Vieira M L G, Esquerdo VM, Nobre LR, et al. Journal of Industrial and Engineering Chemistry 20(5):3387-3393,(2014).

4.Liu Y, Kang Y, Huang D, et al.. Journal of Chemical Technology and Biotechnology,87(7):10101016,(2012).

5.Jaime Lo'pez-Cervantes.Adsorption Science \& Technology0(0) 1-18, 2017

6. I. Vogel, "A Textbook of practical organic chemistry", $3^{\text {rd }}$ ed., Longmans, Green and Co. Ltd., London, pp. 622- 623(1964)

7. S. S. Baral, Ph. D. Thesis, National institute of technology Roukela India(2007)

8.Raiad.T.Alabade.,Ph.D. College of Education, University of Mosul(2010) .(In Arabic)

9. A. Khaled, A. El Nemr, A. El-Sikaily and O. Abdelwahab, J. Hazard. Mater., 165, pp. 100-110 (2009).

10. A. A. Dima, M. Sc. Thesis, University of Addis Ababa,(2008).

11. S. S. Reddy, B. Kotaiah, N. S. P. Reddy, M. Velu, Turk. J. Eng. Env. Sci., 30, 370(2006).

12. G. Mckay. Chem. Eng. J: 27, 187-195,(1983).

13. W. J. Weberst and J. C. Morris, J. Saint, Eng. Div. Am. Soc. Civ. Eng, 89, pp. 31-60,(1963).

14. Y. Bulut, N. Gozubenli, H. Aydm, J. Hazard. Mater., 144, pp. 303-305,(2007). .

15. R. K. Rajoriya, B. Prasad, I. M. Mishra, K. L. Wasewar, chem. Biochem. Eng. Q. 21, pp. 221224(2007).

16. C. H. Wu, J. Hazard. Mater., 144, pp. 96-98,(2007). 